IZA DP No. 7963

On the Optimal Composition of Committees

Ruth Ben-Yashar

Leif Danziger

February 2014

Forschungsinstitut zur Zukunft der Arbeit Institute for the Study of Labor 


\title{
On the Optimal Composition of Committees
}

\author{
Ruth Ben-Yashar
}

Bar-Ilan University

Leif Danziger

Ben-Gurion University and IZA

\section{Discussion Paper No. 7963 \\ February 2014}

\author{
IZA \\ P.O. Box 7240 \\ 53072 Bonn \\ Germany \\ Phone: +49-228-3894-0 \\ Fax: +49-228-3894-180 \\ E-mail: iza@iza.org
}

Any opinions expressed here are those of the author(s) and not those of IZA. Research published in this series may include views on policy, but the institute itself takes no institutional policy positions. The IZA research network is committed to the IZA Guiding Principles of Research Integrity.

The Institute for the Study of Labor (IZA) in Bonn is a local and virtual international research center and a place of communication between science, politics and business. IZA is an independent nonprofit organization supported by Deutsche Post Foundation. The center is associated with the University of Bonn and offers a stimulating research environment through its international network, workshops and conferences, data service, project support, research visits and doctoral program. IZA engages in (i) original and internationally competitive research in all fields of labor economics, (ii) development of policy concepts, and (iii) dissemination of research results and concepts to the interested public.

IZA Discussion Papers often represent preliminary work and are circulated to encourage discussion. Citation of such a paper should account for its provisional character. A revised version may be available directly from the author. 
IZA Discussion Paper No. 7963

February 2014

\section{ABSTRACT}

\section{On the Optimal Composition of Committees}

This paper derives a simple characterization of how to optimally divide an organization's experts into different decision-making committees. The focus is on many three-member committees that make decisions by a simple majority rule. We find that the allocation of experts to committees is optimal if and only if it minimizes the sum of the products of the experts' skills in each committee. As a result, given the experts of any two committees, the product of the experts' skills should be as similar as possible in the two committees, and it is never optimal to have the three worst experts in one committee and the three best experts in another.

JEL Classification: D71

Keywords: optimal composition of committees, simple majority rule

Corresponding author:

Leif Danziger

Department of Economics

Ben-Gurion University

Beer-Sheva 84105

Israel

E-mail: danziger@bgu.ac.il 


\section{Introduction}

Many organizations make decisions by means of different committees. Thus, the division of experts into committees is essential for making correct decisions. Following Condorcet (1785) who first studied formally decision making in a committee, the standard assumption in the literature is that the composition of the committee is given. ${ }^{1}$ To the best of our knowledge, the only exception is Ben-Yashar and Danziger (2011) who examined aspects of how to optimally allocate experts with different abilities into committees. That paper made the strong assumptions that there are only two committees and an even number of experts at each of various ability levels. The main issue was not to derive an optimal allocation of experts to committees, but to answer the limited question of whether an optimal allocation entails that the two committees should have an identical composition in terms of the experts' abilities, i.e., that the committees should be symmetric. The central finding was that experts with different ability levels should not generally be evenly divided among committees. In other words, asymmetric committees may be preferable to symmetric committees.

In the present study, we consider many three-member committees and all possible configurations of the experts' abilities. In particular, we do not restrict the number of experts at various ability levels to be a multiple of the number of committees. The purpose is to characterize the optimal composition of the committees. To this end, we examine an organization that needs to make decisions on whether to accept or reject various proposals. The organization employs experts who strive to make the correct decision for the organization

\footnotetext{
1 See Grofman and Feld (1988), Young (1995), Ben-Yashar and Nitzan (1997), Berend and Sapir (2007), Dietrich and List (2008, 2013a), and Peleg and Zamir (2012). Further, Ahn and Oliveros (2010), Bozbay, Dietrich, and Peters (2011), and De Clippel and Eliaz (2012) study how to efficiently aggregate judgments when several issues are involved, as a link may then exist between the optimal decision for each issue. Their concern is whether the aggregation should be based on premise or outcome, and about the associated doctrinal paradox.
} 
regarding each proposal. The decision makers are divided between a given number of committees that work in parallel and decide on each proposal assigned to it. Each expert votes for or against a proposal assigned to his committee according to what he believes is the best decision for the organization for that particular proposal. A committee makes its decision by simple majority rule on each proposal assigned to it. The objective of the organization is to determine the optimal composition of the committees, i.e., the composition that maximizes the average probability of making correct decisions.

We derive an extremely simple expression for how to allocate the experts into the different committees. As we show, the optimal allocation minimizes the sum of the products of the experts' skills in each committee, where an expert's skill is defined by the extent to which the probability that he votes correctly exceeds that of a random choice. It follows that, given the experts of any two of the committees, the committees should be composed so that the product of the members' skills in each committee is as similar as possible. In particular, if there are only two types of experts, high- and low-skilled, ${ }^{2}$ the composition of the committees should be as symmetric, i.e., as similar as possible. It also follows that if the experts can have many skill levels, it is never optimal that one committee is composed of the three experts who have the highest skills and another of the three experts who have the lowest skills. Finally, if there are three types of experts, then if possible, it is optimal that each committee be composed of one expert from each skill level.

\footnotetext{
${ }^{2}$ As, for example, in a legal system where decisions are made by courts having three judges and where judges can be either more experienced or less experienced.
} 


\section{The Model}

We consider an organization that needs to make binary decisions on many proposals with the help of a given number $Z>1$ of separate committees. Examples would include a firm that has to decide about different investment projects or a justice system that has to determine different defendants' guilt or innocence. There are $3 Z$ experts and each expert will be a member of one committee. The proposals are assigned equally between the committees each of which consists of three different experts who for each proposal uses a simple majority vote to decide whether to accept or reject that proposal.

For each proposal, the correct decision is either acceptance or rejection. An expert must vote either for or against a proposal assigned to his committee. The ability of expert $i \in I$, $I=\{1, \ldots, 3 Z\}$ can be represented by the probability $p_{i} \in\left(\frac{1}{2}, 1\right)$ that he votes for the correct decision for a proposal. His vote is independent of the other experts' votes.

In order to avoid trivial cases where there is only one possible composition of the committees in terms of the experts' abilities, we assume that at most $3 Z-2$ experts have the same ability. ${ }^{3} \quad$ A composition of the committees is a partition of the $I$ experts into $Z$ three-member committees denoted by $c=\left\{c_{1}, \ldots, c_{Z}\right\}$. The set of all such possible partitions is denoted by $C$. Formally,

$$
C=\left\{c \mid c \text { is a partition of } I \text { where }\left|c_{z}\right|=3 \text { for each } c_{z} \in c\right\} \text {. }
$$

Let $G\left(c_{z}\right)$ be the probability that committee $c_{z}$ makes the correct decision by simple majority rule on a proposal assigned to it. The organization seeks to allocate the experts

3 Thus, there are at most

$$
\frac{(3 Z) !}{Z !(3 !)^{Z}}
$$

possible compositions of committees in terms of the experts' abilities. 
to the $Z$ committees, i.e., to choose $c \in C$ in order to maximize the average probability $(1 / Z) \sum_{c_{z} \in c} G\left(c_{z}\right)$ that the committees make correct decisions on their proposals. ${ }^{4}$

\section{The Optimal Allocation of Experts}

Let $q_{i} \equiv p_{i}-\frac{1}{2}$ denote the skill of expert $i$; that is, how much the probability that he votes correctly exceeds that of a random choice. We have

Theorem 1: A $c \in C$ is optimal if and only if it minimizes

$$
\sum_{c_{z} \in c} \prod_{i \in c_{z}} q_{i}
$$

Proof: Suppose that $c_{z}=\{j, k, \ell\}$. Then

$$
\begin{aligned}
G\left(c_{z}\right) & =p_{j} p_{k}\left(1-p_{\ell}\right)+p_{j}\left(1-p_{k}\right) p_{\ell}+\left(1-p_{j}\right) p_{k} p_{\ell}+p_{j} p_{k} p_{\ell} \\
& =p_{j} p_{k}+p_{j} p_{\ell}+p_{k} p_{\ell}-2 p_{j} p_{k} p_{\ell} \\
& =\frac{1}{2}+\frac{1}{2}\left(q_{j}+q_{k}+q_{\ell}\right)-2 q_{j} q_{k} q_{\ell}
\end{aligned}
$$

from which it follows that

$$
\begin{aligned}
& \frac{1}{Z} \sum_{c_{z} \in c} G\left(c_{z}\right) \\
= & \frac{1}{2}+\frac{1}{2 Z} \sum_{i=1}^{3 Z} q_{i}-\frac{2}{Z} \sum_{c_{z} \in c} \prod_{i \in c_{z}} q_{i} .
\end{aligned}
$$

4 This is equivalent to maximizing the expected number of correct decisions. Given our framework, it is a Nash equilibrium and therefore reasonable to assume that the experts vote according to their true assessment, i.e., informatively (Austen-Smith and Banks, 1996; and Ben-Yashar and Milchtaich, 2007). Under other circumstances, strategic considerations may influence the experts' voting behavior (Feddersen and Pesendorfer, 1998; Dekel and Piccione, 2000; Austen-Smith and Feddersen, 2006; and Gerardi and Yariv, 2007). With the experts voting informatively and deciding by a simple majority rule, our results hold whether the proposals are independent or dependent. Thus, there is no need to assume even logical independence of the proposals (Dietrich and List, 2013b). 
Since the skills of the experts and hence $\sum_{i=1}^{3 Z} q_{i}$ are given, choosing $c \in C$ to maximize $(1 / Z) \sum_{c_{z} \in c} G\left(c_{z}\right)$ is equivalent to choosing $c \in C$ to minimize $\sum_{c_{z} \in c} \prod_{i \in c_{z}} q_{i}$. That is, an optimal $c$ minimizes $\sum_{c_{z} \in c} \prod_{i \in c_{z}} q_{i}$.

According to Theorem 1, an optimal allocation of experts minimizes the sum of the products of the experts' skills in each committee, and conversely, minimizing the sum of the products leads to an optimal allocation. Of course, Theorem 1 does not imply that having experts with higher skills reduces the likelihood of correct decisions. Rather, the theorem reflects the fact that within a three-member committee the different experts' skills are substitute inputs in producing correct decisions. ${ }^{5} \quad$ As the minimal $\sum_{c_{z} \in c} \prod_{i \in c_{z}} q_{i}$ might be achieved by different compositions of the committees in terms of the experts' skills, an optimal composition is generally not unique. ${ }^{6}$

Even if the organization is stuck with deadwood, i.e., useless individuals due e.g. to collective agreements or the absence of mandatory retirement, Theorem 1 will remain relevant if we allow "experts" who have no skills, i.e., for whom $q_{i}=0 .{ }^{7}$ Thus, if there are less than

5 That is,

$$
\frac{\partial^{2}\left[(1 / Z) \sum_{c_{z} \in c} G\left(c_{z}\right)\right]}{\partial q_{i} \partial q_{i^{\prime}}}<0
$$

if expert $i$ and expert $i^{\prime}$ are members of the same committee.

6 To see this, suppose that $Z=2$ and that the six experts have different skills. Furthermore, assume that $q_{1} q_{2}=q_{3} q_{4}, q_{5}=\left(q_{1} q_{2}\right)^{1 / 2}$, and $q_{6}=\left(q_{1} q_{2}\right)^{1 / 2+\epsilon}$, where $\epsilon>0$. Then,

$$
\begin{aligned}
q_{1} q_{2}\left(q_{1} q_{2}\right)^{1 / 2}+q_{3} q_{4}\left(q_{1} q_{2}\right)^{1 / 2+\epsilon} & =q_{1} q_{2}\left(q_{1} q_{2}\right)^{1 / 2+\epsilon}+q_{3} q_{4}\left(q_{1} q_{2}\right)^{1 / 2} \\
\Leftrightarrow q_{1} q_{2} q_{5}+q_{3} q_{4} q_{6} & =q_{1} q_{2} q_{6}+q_{3} q_{4} q_{5} .
\end{aligned}
$$

Hence, the partition $\{1,2,5\}$ and $\{3,4,6\}$ of experts and the partition $\{1,2,6\}$ and $\{3,4,5\}$ of experts have the same sum of the products of the experts' skills in each committee. Furthermore, if $\epsilon$ is sufficiently small, the sum is smaller than for any other partition. Accordingly, there are two optimal compositions of the committees.

7 Preferably, such "experts" should be prevented from being committee members or should be made to abstain in the voting. In a model with costly voting, Börgers (2004) shows that abstentions should be allowed. 
$Z$ "experts" with no skills, the optimal composition of the committees requires that each of these should be placed in a different committee and that of the rest of the experts, those with the most skill should also be placed in those committees. Furthermore, if there are at least $Z$ "experts" with no skills, at least one should be placed in each committee since then $\prod_{i \in c_{z}} q_{i}=0 \forall c_{z} \in c$, with the allocation of the other experts being immaterial.

Theorem 1 implies that the optimal allocation of experts may not be reached by sequentially allocating the experts to the committees according to their skills. Suppose, for example, that there are only two committees and one expert with skill 0.4 , two experts with skill 0.3 , and three experts with skill 0.1 . It would then be optimal that one committee consists of experts with skills $0.4,0.1$, and 0.1 , and another committee consists of experts with skills $0.3,0.3$, and 0.1 . The value of expression $(1)$ is $0.4 \cdot 0.1 \cdot 0.1+0.3 \cdot 0.3 \cdot 0.1=0.013$. On the other hand, a sequential allocation would lead to one committee consisting of experts with skills $0.4,0.3$, and 0.1 , and another of experts with skills $0.3,0.1$, and 0.1 . The value of expression (1) would be $0.4 \cdot 0.3 \cdot 0.1+0.3 \cdot 0.1 \cdot 0.1=0.015$, which shows that a sequential allocation by decreasing skill is not optimal.

For the following corollary, let $I_{z z^{\prime}} \equiv\{j, k, \ell, m, n, o\}$ denote the six experts of two committees $c_{z}$ and $c_{z^{\prime}}$ in an optimal $c \in C$. Also, given $I_{z z^{\prime}}$, let $c^{\prime}=\left\{c_{v}, c_{v^{\prime}}\right\}$ denote a partition of the six experts into two three-member committees, and let

$$
C_{z z^{\prime}}=\left\{c^{\prime} \mid c^{\prime} \text { is a partition of } I_{z z^{\prime}} \text { where }\left|c_{z}\right|=3 \text { for each } c_{z} \in c^{\prime}\right\}
$$

be the set of all possible partitions of the experts $I_{z z^{\prime}}$ into two three-member committees.

Corollary 1: Given two committees $c_{z}$ and $c_{z^{\prime}}$ in an optimal $c$, for all $c^{\prime} \in C_{z z^{\prime}}$ :

$$
\left|\prod_{i \in c_{z}} q_{i}-\prod_{i \in c_{z^{\prime}}} q_{i}\right| \leq\left|\prod_{i \in c_{v}} q_{i}-\prod_{i \in c_{v^{\prime}}} q_{i}\right| .
$$


Proof: Suppose that an optimal composition of the two committees $c_{z}$ and $c_{z^{\prime}}$ are given by $\{j, k, \ell\}$ and $\{m, n, o\}$, and w.l.o.g. that $q_{j} q_{k} q_{\ell} \geq q_{m} q_{n} q_{o}$. If $q_{j}<q_{m}$, it immediately follows that

$$
q_{j} q_{k} q_{\ell}-q_{m} q_{n} q_{o}<q_{k} q_{\ell} q_{m}-q_{j} q_{n} q_{o}
$$

But if $q_{j} \geq q_{m}$, Theorem 1 shows that $q_{k} q_{\ell} \leq q_{n} q_{o}$ and therefore that

$$
\begin{aligned}
q_{k} q_{\ell}\left(q_{j}+q_{m}\right) & \leq q_{n} q_{o}\left(q_{j}+q_{m}\right) \\
\Rightarrow q_{j} q_{k} q_{\ell}-q_{m} q_{n} q_{o} & \leq q_{j} q_{n} q_{o}-q_{k} q_{\ell} q_{m} .
\end{aligned}
$$

Since all other compositions of the two committees can be obtained by switching a single expert between $c_{z}$ and $c_{z^{\prime}}$, it can be concluded that $\left\{c_{z}, c_{z^{\prime}}\right\}$ minimizes $\left|\prod_{i \in c_{z}} q_{i}-\prod_{i \in c_{z^{\prime}}} q_{i}\right|$ for $c^{\prime} \in C_{z z^{\prime}}$.

Thus, an optimal allocation requires that, given the experts of any two of the $Z$ committees, the product of the members' skills should be as similar as possible in the two committees. In particular, if possible, in an optimal allocation the product of the experts' skills should be the same. In the special case where experts can have only two skill levels, high and low, the committees in the optimal $c \in C$ should be as symmetric as possible; i.e., there should not be a committee with three high-skilled (low-skilled) experts and another with no or only one high-skilled (low-skilled) expert. The corollary illustrates the principle that diversity within committees is desirable while polarization between committees is undesirable.

The following two corollaries show what could beneficially be implemented by an organization that does not possess complete information about the skills of the experts. In 
particular, this would be the case if the organization knows only the ranking and not the levels of the experts' skills.

Corollary 2: In an optimal $c \in C$, the three worst experts cannot be members of one committee and the three best experts members of another.

Proof: Suppose that $q_{j}, q_{k}$, and $q_{\ell}$ are the skills of the three worst experts and $q_{m}, q_{n}$, and $q_{o}$ the skills of the three best. Since there are at least two experts with different skills than the other experts, it follows w.l.o.g. that there exist skills satisfying $q_{\ell}<q_{o}, q_{j} \leq q_{m}$, and $q_{k} \leq q_{n}$. Therefore, if either $q_{j}<q_{m}$ or $q_{k}<q_{n}$, then

$$
\begin{aligned}
q_{j} q_{k} & <q_{m} q_{n} \\
\Rightarrow \quad q_{j} q_{k}\left(q_{o}-q_{\ell}\right) & <q_{m} q_{n}\left(q_{o}-q_{\ell}\right) \\
\Rightarrow q_{j} q_{k} q_{o}+q_{\ell} q_{m} q_{n} & <q_{j} q_{k} q_{\ell}+q_{m} q_{n} q_{o} .
\end{aligned}
$$

On the other hand, if both $q_{j}=q_{m}$ and $q_{k}=q_{n}$, then it must be the case that $q_{\ell}<q_{j}=q_{m}=$ $q_{k}=q_{n}<q_{o}$. Therefore,

$$
\begin{aligned}
0 & <\left(q_{n}-q_{\ell}\right)\left(q_{o}-q_{k}\right) \\
\Rightarrow \quad q_{k} q_{n}+q_{\ell} q_{o} & <q_{k} q_{\ell}+q_{n} q_{o} \\
\Rightarrow q_{j} q_{k} q_{n}+q_{\ell} q_{m} q_{o} & <q_{j} q_{k} q_{\ell}+q_{m} q_{n} q_{o} .
\end{aligned}
$$

Consequently, a $c$ containing the committees $\{j, k, \ell\}$ and $\{m, n, o\}$ cannot be optimal.

Corollary 2 shows that an extremely asymmetric composition of the committees cannot be optimal, i.e., an organization should not allocate the three worst experts to one committee and the three best experts to another. This corollary is another example of the desirability of symmetry between committees and the corresponding asymmetry within committees. 
Corollary 3: If there are $Z$ experts at each of three different skill levels, the optimal $c \in C$ is unique and symmetric. Thus, each committee includes one expert at each skill level, i.e., the optimal $c=\left\{c_{1}, \ldots, c_{Z}\right\}$ is such that $c_{1}=\ldots=c_{Z}$.

Proof: Let committee $c_{z}$ be composed of $a_{j z}, a_{k z}$, and $a_{\ell z}$ experts with skill $q_{j}, q_{k}$, and $q_{\ell}$, respectively. Then expression (1) can be written as

$$
\begin{aligned}
& \sum_{z=1}^{Z} q_{j}^{a_{j z}} q_{k}^{a_{k z}} q_{\ell}^{a_{\ell z}} \\
= & \sum_{z=1}^{Z-1} q_{j}^{a_{j z}} q_{k}^{a_{k z}} q_{\ell}^{a_{\ell z}}+q_{j}^{Z-\sum_{z=1}^{Z-1} a_{j z}} q_{k}^{Z-\sum_{z=1}^{Z-1} a_{k z}} q_{\ell}^{Z-\sum_{z=1}^{Z-1} a_{\ell z}} .
\end{aligned}
$$

If we ignore that $a_{j z}, a_{k z}$, and $a_{\ell z}$ for all $z$ must equal $0,1,2$, or 3 , differentiating with respect to $a_{j z}, a_{k z}$, and $a_{\ell z}$ for all $z$ shows that expression (2) reaches a minimum if

$$
q_{j}^{a_{j z}} q_{k}^{a_{k z}} q_{\ell}^{a_{\ell z}}-q_{j}^{Z-\sum_{z=1}^{Z-1} a_{j z}} q_{k}^{Z-\sum_{z=1}^{Z-1} a_{k z}} q_{\ell}^{Z-\sum_{z=1}^{Z-1} a_{\ell z}}=0
$$

for all $a_{j z}$ 's, $a_{k z}$ 's, and $a_{\ell z}$ 's. ${ }^{8} \quad$ Hence, at a minimum we have that $a_{j z}=a_{k z}=a_{\ell z}=1$ for all $z$, making the products $q_{j}^{a_{j z}} q_{k}^{a_{k z}} q_{\ell}^{a_{\ell z}}=q_{j} q_{k} q_{\ell}$ for all $z$. Since this solution remains feasible also when the $a_{j z}$ 's, $a_{k z}$ 's, and $a_{\ell z}$ 's are constrained to equal $0,1,2$, or 3 , we conclude that symmetric committees minimize the sum of the products of the experts' skills in each committee and are uniquely optimal.

Corollary 3 represents a special case where, due to the number of experts at each of three different skill levels being equal to the number of committees, symmetric committees are uniquely optimal. Ben-Yashar and Danziger (2011) have shown that if there are only two committees with each having more than three members, then the optimal committees are generally not symmetric even if there is an even number of experts at each of various skill

\footnotetext{
8 The second-order conditions for a minimum are satisfied.
} 
levels. However, they also showed that in the case of two three-member committees and the existence of two experts at each of three skill levels, one of each type of expert should be allocated to each of the two committees. Corollary 3 therefore generalizes their symmetry result to the case of more than two committees.

\section{Conclusion}

The problem of how to benefit as much as possible from experts with different abilities is nontrivial for an organization that is forced to divide the experts into many decision-making committees. We have given a simple characterization of how to optimally allocate the experts into three-member committees. Our main finding is that an allocation of experts is optimal if and only if it minimizes the sum of the products of the experts' skills in each committee. This reflects the important role played by the substitutability of the experts' skills in making correct decisions. One consequence is that an extremely asymmetric allocation of experts into committees - so that one committee is composed of the three least qualified experts and another of the three most qualified experts - is never optimal. Another consequence is that if symmetric committees are possible, then they are uniquely optimal. 


\section{References}

Ahn, D.S., Oliveros, S., 2010. The Condorcet jur(ies) theorem. Working Paper.

Austen-Smith, D., Banks, J.S., 1996. Information aggregation, rationality, and the Condorcet jury theorem. American Political Science Review 90, 34-45.

Austen-Smith, D., Feddersen, T., 2006. Deliberation, preference uncertainty, and voting rules. American Political Science Review 100, 209-218.

Ben-Yashar, R., Danziger, L., 2011. Symmetric and asymmetric committees. Journal of Mathematical Economics 47, 440-447.

Ben-Yashar R., Milchtaich, I., 2007. First and second best voting rules in committees. Social Choice and Welfare 29, 453-486.

Ben-Yashar, R., Nitzan, S., 1997. The optimal decision rule for fixed-size committees in dichotomous choice situations: The general result. International Economic Review 38, 175-186.

Berend, D., Sapir, L., 2007. Monotonicity in Condorcet's jury theorem with dependent voters. Social Choice and Welfare 28, 507-528.

Bozbay, I., Dietrich, F., Peters, H., 2011. Judgment aggregation in search for the truth. Working Paper.

Börgers, T., 2004. Costly voting. American Economic Review 94, 57-66.

Condorcet, N.C., 1785. Essai sur l'application de l'analyse à la probabilitè des dècisions rendues à la pluralitè des voix, Paris. In: I. McLean and F. Hewitt, translators, 1994.

De Clippel, G., Eliaz, K., 2012. Premise-based versus outcome-based information aggregation. Working Paper.

Dekel E., Piccione, M., 2000. Sequential voting procedures in symmetric binary elections. Journal of Political Economy 108, 34-55. 
Dietrich, F., List, C., 2008. Judgment aggregation without full rationality. Social Choice and Welfare 31, 15-39.

Dietrich, F., List, C., 2013a. Propositionwise judgment aggregation: The general case. Social Choice and Welfare 40, 1067-1095.

Dietrich, F., List, C., 2013b. Probabilistic opinion pooling generalized - Part one: General agendas. Working Paper.

Feddersen, T., Pesendorfer, W., 1998. Convicting the innocent: The inferiority of unanimous jury verdicts. American Political Science Review 92, 23-35.

Gerardi, D., Yariv, L., 2007. Deliberative voting. Journal of Economic Theory 134, 317-338.

Grofman, B., Feld, S.L., 1988. Rousseau's general will: A Condorcet perspective. American Political Science Review 82, 567-576.

Peleg, B., Zamir, S., 2012. Extending the Condorcet jury theorem to a general dependent jury. Social Choice and Welfare 39, 91-125.

Young, P., 1995. Optimal voting rules. Journal of Economic Perspectives 9, 51-64. 